\title{
REVIEW
}

\section{Neuroimaging features of C9ORF72 expansion}

\author{
Jennifer S Yokoyama and Howard J Rosen*
}

\begin{abstract}
Hexanucleotide expansion intronic to chromosome 9 open reading frame 72 (C9ORF72) has recently been identified as the most common genetic cause of both familial and sporadic amyotrophic lateral sclerosis and of frontotemporal dementia with or without concomitant motor neuron disease. Given the common frequency of this genetic aberration, clinicians seek to identify neuroimaging hallmarks characteristic of C9ORF72-associated disease, both to provide a better understanding of the underlying degenerative patterns associated with this mutation and to enable better identification of patients for genetic screening and diagnosis. A survey of the literature describing C9ORF72 neuroimaging thus far suggests that patients with this mutation may demonstrate symmetric frontal and temporal lobe, insular, and posterior cortical atrophy, although temporal involvement may be less than that seen in other mutations. Some studies have also suggested cerebellar and thalamic involvement in C9ORF72associated disease. Diffuse cortical atrophy that includes anterior as well as posterior structures and subcortical involvement thus may represent unique features of C9ORF72.
\end{abstract}

Although linkage to chromosome $9 \mathrm{p}$ in families was established in 2006 [1], the causative hexanucleotide repeat expansion in a non-coding region of chromosome 9 open reading frame 72 (C9ORF72) was only recently discovered [2,3]. Expansion of C9ORF72 contributes approximately $20 \%$ to $50 \%$ to familial [2-5] and $7 \%$ to $20 \%$ to sporadic amytrophic lateral sclerosis (ALS) $[3,4,6]$ and $12 \%$ to $20 \%$ to familial and $2 \%$ to $16 \%$ to sporadic frontotemporal dementia (FTD) with or without concomitant motor neuron disease (FTD-MND) [2,7-9]. Diagnosis of primary progressive aphasia (PPA) has also been

*Correspondence: hrosen@memory.ucsf.edu

Memory and Aging Center, Department of Neurology, University of California, San Francisco, 675 Nelson Rising Lane, Box 1207, San Francisco, CA 94158, USA documented for some carriers of C9ORF72 expansion $[3,10]$. Given that C9ORF72 expansion likely represents the most common genetic cause for FTD/ALS, many clinicians seek to identify features specific to this mutation to assist in the anticipation of disease onset in families and assessment of disease severity in patients. Here we describe the small body of literature on the neuroimaging features of C9ORF72 which has emerged since its discovery. We summarize these features in the context of other FTD-related gene mutations and highlight unique imaging features that may provide insight into the pathogenic role of C9ORF72 expansion.

\section{C9ORF72 neuroimaging features}

Most neuroimaging studies on C9ORF72 thus far have examined atrophy patterns by using T1-weighted magnetic resonance imaging (MRI) in symptomatic patients with the behavioral variant of FTD (bvFTD) or in combined cohorts of all mutation carriers representing clinical diagnoses of bvFTD, ALS, FTD-MND, and/or PPA. In these contexts, C9ORF72 expansion has been associated primarily with relatively symmetrical (bilateral) atrophy most prominent in the frontal and temporal lobes and the insula (Table 1), which are all regions previously implicated in FTD. Whereas one group found a predominance of temporal atrophy [9], other studies have found less temporal lobe involvement in C9ORF72 mutation carriers $\left(\mathrm{C}^{+}\right)$as compared with patients with other FTD mutations [11] and sporadic disease [12,13]. The group with predominant temporal atrophy was composed of a significantly larger proportion of PPAdiagnosed patients than other studies, which may explain this difference in findings and highlights the heterogeneity in $\mathrm{C}^{+}$-associated diagnoses. C9ORF72 mutation carriers may also harbor several subtle neuroimaging features that are uncommon in sporadic bvFTD and that distinguish it from other mutations (described in detail in the following section). Most notably, $\mathrm{C}^{+}$patients appear to have more parietal and occipital cortical involvement $[8,9,11-14]$, so that cortical atrophy often appears quite diffuse (Table 1). This diffuse atrophy pattern is much less common in other genetic and sporadic forms of FTD and may be a hallmark of C9ORF72 expansion. Interestingly, some $\mathrm{C}^{+}$patients have been described as clinically affected yet demonstrate no visually detectable brain 
Table 1. Summary of C9ORF72 neuroimaging studies

\begin{tabular}{|c|c|c|c|c|}
\hline Study & $\begin{array}{l}\text { Diagnostic groups } \\
\text { included }\end{array}$ & $\begin{array}{l}\text { Atrophy patterns compared } \\
\text { with normal controls }\end{array}$ & $\begin{array}{l}\text { Atrophy patterns compared } \\
\text { with sporadic bvFTD }\end{array}$ & $\begin{array}{l}\text { Atrophy patterns compared } \\
\text { with other mutations }\end{array}$ \\
\hline $\begin{array}{l}\text { Boxer et al. [12] } \\
(2011)\end{array}$ & $\begin{array}{l}n=5 \\
(4 \text { bvFTD and } 1 \text { ALS) }\end{array}$ & $\begin{array}{l}C 9^{+} \text {patients showed atrophy } \\
\text { in bilateral frontal, temporal, } \\
\text { and parietal and right occipital } \\
\text { regions. }\end{array}$ & & \\
\hline $\begin{array}{l}\text { Simón-Sánchez } \\
\text { et al. [9] (2012) }\end{array}$ & $\begin{array}{l}\mathrm{n}=32 \\
(\mathrm{bvFTD}, \mathrm{ALS}, \text { and PPA) }\end{array}$ & $\begin{array}{l}\mathrm{C} 9^{+} \text {patients showed } \\
\text { 'predominantly' frontotemporal } \\
\text { atrophy in } 23 \% \text { and temporal } \\
\text { atrophy in } 42 \% \text {. Thirteen percent } \\
\text { showed generalized atrophy, and } \\
9 \% \text { showed no visible atrophy. } \\
\text { Atrophy extended to the parietal } \\
\text { region in } 31 \% \text { and included the } \\
\text { cerebellum in } 25 \% \text {. }\end{array}$ & & $\begin{array}{l}C 9^{+} \text {patients, compared with } \\
\text { MAPT and GRN carriers, more } \\
\text { often showed temporally } \\
\text { predominant atrophy. MAPT and } \\
\text { GRN were more often associated } \\
\text { with frontally predominant } \\
\text { atrophy. }\end{array}$ \\
\hline $\begin{array}{l}\text { Mahoney et al. [10] } \\
(2012)\end{array}$ & $\begin{array}{l}\mathrm{n}=16 \\
(12 \text { bvFTD, } 3 \text { FTD-MND, } \\
\text { and } 1 \text { nfvPPA) }\end{array}$ & $\begin{array}{l}\mathrm{CP}^{+} \text {patients showed atrophy } \\
\text { in the left orbitofrontal cortex, } \\
\text { left frontal operculum, bilateral } \\
\text { cerebellum, and bilateral } \\
\text { thalamus. }\end{array}$ & & $\begin{array}{l}C 9^{+} \text {patients showed more } \\
\text { atrophy in the PFC and } \\
\text { cerebellum compared with } \\
\text { MAPT carriers and more atrophy } \\
\text { in the left PFC compared with } \\
\text { GRN carriers. MAPT showed } \\
\text { more atrophy in temporal lobe, } \\
\text { including hippocampus and } \\
\text { amygdala, than C9+ patients. GRN } \\
\text { showed more atrophy in the left } \\
\text { temporal lobe, postcentral gyri, } \\
\text { and inferior frontal gyri than C } 9^{+} \\
\text {patients. }\end{array}$ \\
\hline $\begin{array}{l}\text { Boeve et al. [8] } \\
(2012)\end{array}$ & $\begin{array}{l}\mathrm{n}=18 \\
(14 \text { bvFTD, } 3 \text { FTD-ALS, } \\
\text { and } 1 \text { ALS) }\end{array}$ & $\begin{array}{l}\text { Fourteen of eighteen } \mathrm{C}^{+} \\
\text {patients showed frontal atrophy. } \\
\text { Eight showed temporal atrophy. } \\
\text { Five showed parietal atrophy. } \\
\text { Three } C 9^{+} \text {patients had no } \\
\text { detectable atrophy. }\end{array}$ & & \\
\hline $\begin{array}{l}\text { Whitwell et al. [11] } \\
(2012)\end{array}$ & $\mathrm{n}=19$ & $\begin{array}{l}\mathrm{Cg}^{+} \text {patients showed diffuse } \\
\text { atrophy involving the frontal, } \\
\text { temporal, parietal, and occipital } \\
\text { lobes. }\end{array}$ & $\begin{array}{l}\mathrm{C} 9^{+} \text {patients showed more atrophy } \\
\text { in parietal, occipital, lateral, frontal, } \\
\text { and cerebellar regions compared } \\
\text { with sporadic FTD. Sporadic FTD } \\
\text { showed more atrophy in the medial } \\
\text { frontal lobe. }\end{array}$ & $\begin{array}{l}C 9^{+} \text {patients showed more } \\
\text { atrophy in parietal, occipital, } \\
\text { lateral, frontal, and cerebellar } \\
\text { regions compared with MAPT. } \\
\text { MAPT showed more atrophy in } \\
\text { the anterior temporal regions. }\end{array}$ \\
\hline $\begin{array}{l}\text { Sha et al. [13] } \\
(2012)\end{array}$ & $\begin{array}{l}\text { bVFTD: } \mathrm{n}=13 \\
\text { FTD-MND: } \mathrm{n}=8 \\
\text { (Each diagnosis was } \\
\text { analyzed separately.) }\end{array}$ & $\begin{array}{l}\mathrm{C9^{+ }} \text { patients showed diffuse } \\
\text { frontal anterior temporal, parietal, } \\
\text { and cerebellar and thalamic } \\
\text { atrophy compared with controls. }\end{array}$ & $\begin{array}{l}\text { C9+ patients without MND showed } \\
\text { more parietal and thalamic atrophy } \\
\text { than sporadic bvFTD. Sporadic } \\
\text { FTD showed more medial frontal } \\
\text { atrophy. C } 9^{+} \text {patients with MND } \\
\text { showed more dorsal frontal, } \\
\text { posterior, and cerebellar atrophy } \\
\text { compared with sporadic FTD-MND. }\end{array}$ & \\
\hline
\end{tabular}

ALS, amyotrophic lateral sclerosis; bvFTD, behavioral variant frontotemporal dementia; FTD, frontotemporal dementia; FTD-MND, frontotemporal dementia with motor neuron disease; GRN, mutation in GRN gene; MAPT, mutation in MAPT gene; MND, motor neuron disease; nfvPPA, non-fluent variant of primary progressive aphasia; PFC, prefrontal cortex; PPA, primary progressive aphasia.

atrophy $[8,9,14]$; a recent report described two such patients with slowly progressive bvFTD (bvFTD-SP) characterized by a long disease course and nonprogressive brain atrophy, and both of them were $\mathrm{C}^{+}$ [14].

In addition to finding diffuse cortical atrophy, some groups have found involvement of the cerebellum [9-11, 13] or bilateral thalamus $[10,13,14]$ (or both) in $\mathrm{C}^{+}$, which may further distinguish $\mathrm{C}^{+}$neuroimaging patterns from those of other mutations and suggests that subcortical changes may contribute to symptoms $[10,13]$. Cerebellar findings have been further substantiated pathologically by the presence of ubiquitin/p62-positive, TDP-43-negative neuronal cytoplasmic inclusions in this area in subsets of $\mathrm{C}^{+}$FTD/ALS cases included in the aforementioned neuroimaging studies $[8-10,12]$ as well as 
others [15-18] and may be a unique pathologic finding associated with C9ORF72 expansion [15].

Little assessment of C9ORF72-associated features has yet been performed using neuroimaging modalities beyond T1-weighted MRI. Findings from multimodal imaging, such as positron emission tomography (PET) or single-photon emission computed tomography (SPECT), are most often concordant with structural imaging findings but can sometimes reveal additional information not readily apparent from MRI alone. In $\mathrm{C}^{+}$patients, in whom marked heterogeneity in presentation may complicate diagnosis, complementary findings from other imaging modalities may be particularly informative for confirming clinical and structural imaging findings. For example, Floris and colleagues [19] presented a case report of a patient with C9ORF72 expansion associated with FTD-parkinsonism-upper motor neuron disease. In addition to presenting with prominent behavioral disturbances consistent with bvFTD, the patient presented with marked visuospatial impairment and hallucinations, which, along with parkinsonism, suggested a differential diagnosis of dementia with Lewy bodies. This patient demonstrated bilateral frontotemporal and posterior atrophy on structural MRI. Perfusion SPECT demonstrated reduced uptake bilaterally in both frontotemporal and parietal regions, consistent with structural imaging findings and the behavioral and visuospatial impairments. Genetic screening confirmed pathogenic expansion of C9ORF72 and a diagnosis of bvFTD [19]. Similarly, Khan and colleagues [14] described one C9+ bvFTD-SP patient who had no atrophy upon visual inspection of MRI and had a consistent FDG-PET scan showing results within normal limits. These findings, though concordant across imaging modalities, were interesting given the patient's clinical presentation of bvFTD and suggest disruption of behavior in the context of limited visible changes on both structural and metabolic imaging.

Even within a survey of six more 'typical' $\mathrm{C}^{+}$patients, Boeve and colleagues [8] described a variety of findings from SPECT and PET imaging. In five carriers, SPECT demonstrated significant hypoperfusion in the anterior and middle cingulate gyri in comparison with controls. In one of these patients, there was no visual atrophy in structural MRI at the time of SPECT imaging, and frontal cortical atrophy was more evident only on structural MRI two years later [8], suggesting that early changes in hypometabolism preceded cortical atrophy. In four of five patients who underwent FDG-PET imaging, anterior cingulate demonstrated significant hypometabolism; posterior cingulate metabolism was normal in all four patients, and frontal cortical hypometabolism ranged from mild to severe [8]. Interestingly, the fifth patient demonstrated hypometabolism in parietal/precuneus regions with relative sparing of frontal cortical regions, a pattern more consistent with Alzheimer's disease than FTD/ALS. These findings, though not directly comparable, indicate that multimodal imaging sometimes may reveal abnormalities not detectable with structural MRI alone. This is particularly true when characterizing atypical clinical presentations and also establishes a breadth of imaging variability across $\mathrm{C}^{+}$patients. This high level of heterogeneity across individuals reflects the multitude of clinical phenotypes associated with $\mathrm{C}^{+}$and may distinguish C9ORF72 expansion from other FTDassociated gene mutations, which are described in the next section.

\section{C9ORF72 versus GRN and MAPT neuroimaging characteristics}

Previous studies have assessed the neuroimaging characteristics unique to other FTD-spectrum gene mutations, most notably in granulin (GRN), which encodes the protein progranulin and results in TDP-43 pathology, and in MAPT, the gene coding for the tau protein, which characterizes the other major type of FTD pathology. MAPT mutation carriers are generally characterized by relatively symmetrical atrophy predominantly in the anterior and medial temporal lobes, orbitofrontal cortex, and fornix [7,20]. Whitwell and colleagues [20] also found cerebellar involvement in MAPT mutation carriers. In contrast, GRN mutations are often associated with strongly asymmetric atrophy, affecting either hemisphere and involving the inferior frontal, temporal, and parietal lobes, with additional white matter involvement $[7,20]$. Examples of typical atrophy patterns in $M A P T$, GRN, and C9ORF72 mutation carriers are shown in Figure 1.

Whitwell and colleagues [11] performed modeling to identify neuroimaging predictors of C9ORF72 expansion as compared with GRN and MAPT and found that smaller left sensorimotor cortices, right occipital lobe and left cerebellum, and larger left inferior temporal lobe all independently contributed to a prediction of $\mathrm{C}^{+}$ status. Using 14 of 39 total regions of interest, they could correctly classify C9ORF72 mutation carriers with $74 \%$ accuracy and achieved 93\% classification accuracy with 26 variables [11]. Although neuroimaging hallmarks are more likely to be used in conjunction with, rather than in place of, molecular genetic and family history information [21], the ability to accurately identify $\mathrm{C}^{+}$ patients from other FTD mutation carriers further supports the hypothesis that different genetic lesions result in different patterns of brain atrophy. Identification of gene-specific neuroimaging hallmarks may provide insight into the underlying pattern and type of pathology, which could be important information in the advent of pathology type-specific therapeutic interventions or for use as a biomarker in clinical trials. Previous studies have 


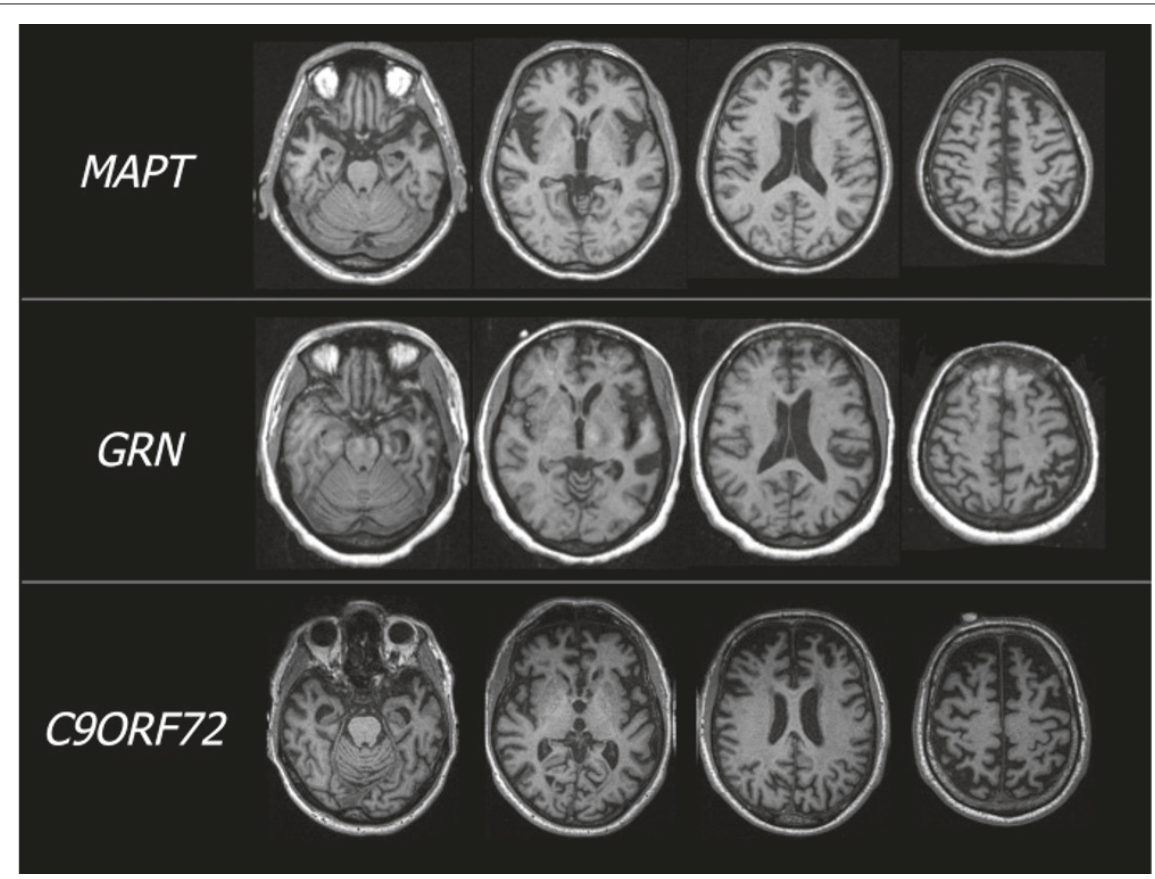

Figure 1. Representative magnetic resonance images for the three most common frontotemporal dementia (FTD)-causing gene mutations. T1-weighted magnetic resonance images are shown for three different patients, each harboring a single mutation in a different gene that causes FTD. The patient with MAPT demonstrates symmetrical atrophy in ventral frontotemporal regions, particularly in the anterior temporal poles, whereas the GRN mutation carrier demonstrates marked asymmetrical atrophy, most notable in dorsal, frontotemporal regions, with additional involvement in posterior areas. However, the patient with C9ORF72 expansion shows diffuse, symmetrical atrophy in frontal, temporal, and parietal cortical regions as well as cerebellum. C9ORF72, chromosome 9 open reading frame 72; GRN, granulin; MAPT, microtubule-associated protein tau.

suggested that FTLD-TDP-43 type may be consistent with specific patterns of structural atrophy [22,23]. Both TDP-43 (harmonized [24]) type A and B pathologies have been associated with C9 $^{+}$FTD/ALS [8-10,16-18] and are broadly consistent with neuroimaging hallmarks for each: type A (Mackenzie type 1, Sampathu type 3) was associated with more dorsal frontotemporal, inferior parietal, striatal, and thalamic atrophy, and type B (Mackenzie type 3, Sampathu type 2) was associated with relatively symmetrical posterior frontal, medial temporal, prefrontal, orbitofrontal, and insular cortex atrophy $[22,23]$. The association of neuroimaging findings and pathology in less common clinical presentations of $\mathrm{C}^{+}$ cases, however, remains to be determined.

The role of genotype in changes in brain structure over time provides another insight into early hallmarks of disease and its underlying phenomenology. Although the sample size was small, Mahoney and colleagues [10] found that annualized rates of brain atrophy were greatest in GRN $(\mathrm{n}=4)$ carriers, followed by carriers of C9ORF72 $(\mathrm{n}=5)$ and MAPT $(\mathrm{n}=6)$, although mean atrophy rates did not differ significantly between groups [25]. Previously, Whitwell and colleagues [26] demonstrated similar findings whereby GRN mutation carriers had higher annual rates of whole-brain atrophy in comparison with MAPT mutation carriers. Boeve and colleagues [8] reported on at least 2 years of longitudinal follow-up in eight $\mathrm{C}^{+}$patients, who showed progression of atrophy specifically in frontal lobes and ventricular enlargement. Previously, GRN mutations were shown to exhibit asymmetric volume loss mainly in inferior frontal, superior temporal, and inferior parietal lobes, precuneus, and cingulate cortex over time [25]. In MAPT mutation carriers, longitudinal volume loss is symmetric and involves anteromedial temporal lobes, orbitofrontal cortex, and white matter tracts, including corpus callosum [25].

Of note, Khan and colleagues [14] described two patients with bvFTD-SP who demonstrated no significant brain atrophy over the course of 3 years and 8 years, respectively; the seeming lack of progressive atrophy contributed some uncertainty to the patients' initial bvFTD diagnosis. A small minority of patients with mutation in C9ORF72 have been described with similar absences of visible brain atrophy in MRI [8,9], and this stands in stark contrast to the often insidious progression of volume loss displayed with the other main gene mutation causing TDP-43 pathology, GRN. The possibility that some patients harboring C9ORF72 repeat 
expansion may not show progressive brain atrophy thus seems quite unusual in comparison with other mutations, and it will be important to investigate potential factors that modify rates of progression, including the number of hexanucleotide repeats, as the technology becomes available.

\section{Thalamic atrophy, subcortical connectivity, and slowly progressive FTD: insights into C9 pathogenicity?}

Broadly, MAPT atrophy is symmetric and more ventral whereas $G R N$ atrophy is asymmetric and more dorsal [25], and this difference may reflect degeneration in different functional networks that may be selectively vulnerable to FTLD [27]. Although initial lesions (genetic, developmental, environmental, and so on) may differentially determine which brain region is first affected, studies in FTD mutation carriers as well as in other diseases strongly suggest that once a degenerative process is set in motion, that process will continue in a circumscribed pattern [25] that may be determined by connections reflecting intrinsic organization of functional brain systems [27]. Zhou and colleagues [28] suggest that neurodegenerative processes may begin within a single 'epicenter' and spread through a specific network of functional paths. In the case of mutation carriers, genetically mediated vulnerability may enhance this spread. Two key questions thus remain: how does C9ORF72 expansion alter vulnerability, and upon what path does it tread?

Findings from published neuroimaging studies thus far suggest that subcortical structures, including the thalamus and cerebellum, may be uniquely affected by mutation in C9ORF72. As reviewed by Schmahmann and colleagues [29], these regions are both interconnected with the entire cerebral cortex. If these subcortical regions serve as the epicenter for C9ORF72 pathology, then their diffuse cortical connectivity may be a clue to the mechanisms leading to the diffuse cortical involvement that seems characteristic of this mutation.

Subcortical involvement may also explain the development of symptoms even in patients who have relatively little cortical atrophy. In a meticulous review, Schmahmann and Pandya [30] describe disconnection syndromes that can occur in the context of specific subcortical involvement of the basal ganglia, thalamus, and cerebellum. The authors propose that neural architecture determines function, that specific connections between subcortical nodes define behavior, and that fiber tracts linking cerebral cortical regions to one another enable the coordination necessary for complex behaviors [30]. In this framework, changes in the connectivity of these subcortical structures with the cortex could account for some of the behavioral, executive function, and motor symptoms that have recently been associated with C9ORF72 FTD/ALS, even in patients who show relatively little cortical atrophy. This hypothesis will have to be addressed in future studies integrating structural and functional imaging methodology and linking them to symptoms $[13,31]$.

\section{Conclusions}

Mutation carriers with FTD demonstrate prominent symmetric atrophy in frontal and temporal lobes and insula. Main hallmarks specific to C9ORF72 may include relatively diffuse changes that involve posterior as well as anterior cortical regions and bilateral thalamic and cerebellar atrophy. Involvement of temporal lobes does not appear to be as prominent in $\mathrm{C}^{+}$patients with bvFTD but is still seen in those with PPA. Occipital and cerebellar atrophy and relative sparing of temporal lobes may be distinguishing features of C9ORF72 relative to $G R N$ - or MAPT-associated disease. Finally, in some expansion carriers, atrophy may not be apparent upon visual inspection of MRI despite clear clinical symptoms, and this may reflect the effects of disease on subcortical structures.

Although significant efforts have been undertaken to characterize C9ORF72 expansion carriers, much of this work has been performed on incomplete archival data or samples of convenience, resulting in diverse datasets and study designs that can be difficult to compare directly, particularly in small cohorts. Future investigations of neuroimaging characteristics in C9ORF72 expansion carriers will require careful clinical characterization and study designs that are properly controlled with respect to diagnosis and image ascertainment. Comparisons of $\mathrm{C}^{+}$ FTD with sporadic disease may further complement work comparing C9ORF72 expansion with other FTDcausing mutations. Furthermore, very few studies have examined the imaging features of C9ORF72 in modalities other than T1-weighted structural MRI. While neuroimaging for diagnostic assessment of mutation carriers will most likely complement-rather than replace-molecular genetic characterization, these signatures may serve a significant role in earlier identification and diagnosis of patients with mild behavioral syndromes or family histories of unknown etiology or both. In addition, neuroimaging may serve a critical role in the prediction of symptoms and in the assessment of drug effects during treatment trials, particularly during preclinical stages of disease. In the future, functional assessment of connectivity and subcortical network mapping may shed light on the mechanistic underpinnings of C9ORF72 pathogenicity, particularly in the context of visually undetectable brain atrophy, and may complement structural imaging in diagnosis and longitudinal assessment. 


\section{Abbreviations}

ALS, amyotrophic lateral sclerosis; bvFTD, behavioral variant frontotemporal dementia; bvFTD-SP, slowly progressive behavioral variant frontotemporal dementia; C9+ $^{+}$, chromosome 9 open reading frame 72 (C9ORF72) expansion carrier; C9ORF72, chromosome 9 open reading frame 72; FTD, frontotempora dementia; FTD-MND, frontotemporal dementia with motor neuron disease; FTLD, frontotemporal lobar degeneration; GRN, granulin; MAPT, microtubuleassociated protein tau; MRI, magnetic resonance imaging; PET, positron emission tomography; PPA, primary progressive aphasia; SPECT, single-photon emission computed tomography.

\section{Competing interests}

The authors declare that they have no competing interests.

\section{Acknowledgments}

JSY was funded by a diversity supplement from the National Institute on Aging-National Institutes of Health (P50-AG023501-08S1, principal investigator: Bruce L Miller). The work was also funded by AG019724.

Published: 16 November 2012

\section{References}

1. Morita M, Al-Chalabi A, Andersen PM, Hosler B, Sapp P, Englund E, Mitchell JE, Habgood JJ, de Belleroche J, Xi J, Jongjaroenprasert W, Horvitz HR, Gunnarsson LG, Brown RH Jr.: A locus on chromosome 9p confers susceptibility to ALS and frontotemporal dementia. Neurology 2006, 66:839-844.

2. DeJesus-Hernandez M, Mackenzie IR, Boeve BF, Boxer AL, Baker M, Rutherford NJ, Nicholson AM, Finch NA, Flynn H, Adamson J, Kouri N, Wojtas A, Sengdy P, Hsiung GY, Karydas A, Seeley WW, Josephs KA, Coppola G, Geschwind DH, Wszolek ZK, Feldman H, Knopman DS, Petersen RC, Miller BL, Dickson DW, Boylan KB, Graff-Radford NR, Rademakers R: Expanded GGGGCC hexanucleotide repeat in noncoding region of C9ORF72 causes chromosome 9p-linked FTD and ALS. Neuron 2011, 72:245-256.

3. Renton AE, Majounie E, Waite A, Simón-Sánchez J, Rollinson S, Gibbs JR, Schymick JC, Laaksovirta H, van Swieten JC, Myllykangas L, Kalimo H, Paetau A, Abramzon Y, Remes AM, Kaganovich A, Scholz SW, Duckworth J, Ding J, Harmer DW, Hernandez DG, Johnson JO, Mok K, Ryten M, Trabzuni D, Guerreiro RJ, Orrell RW, Neal J, Murray A, Pearson J, Jansen IE, et al.: A hexanucleotide repeat expansion in C9ORF72 is the cause of chromosome 9p21-linked ALS-FTD. Neuron 2011, 72:257-268.

4. Byrne S, Elamin M, Bede P, Shatunov A, Walsh C, Corr B, Heverin M, Jordan N, Kenna K, Lynch C, McLaughlin RL, lyer PM, O'Brien C, Phukan J, Wynne B, Bokde AL, Bradley DG, Pender N, Al-Chalabi A, Hardiman O: Cognitive and clinical characteristics of patients with amyotrophic lateral sclerosis carrying a C9orf72 repeat expansion: a population-based cohort study. Lancet Neurol 2012, 11:232-240.

5. Chiò A, Borghero G, Restagno G, Mora G, Drepper C, Traynor BJ, Sendtner M, Brunetti M, Ossola I, Calvo A, Pugliatti M, Sotgiu MA, Murru MR, Marrosu MG, Marrosu F, Marinou K, Mandrioli J, Sola P, Caponnetto C, Mancardi G, Mandich P, La Bella V, Spataro R, Conte A, Monsurrò MR, Tedeschi G, Pisano F, Bartolomei I, Salvi F, Lauria Pinter G, et al.: Clinical characteristics of patients with familial amyotrophic lateral sclerosis carrying the pathogenic GGGGCC hexanucleotide repeat expansion of C9ORF72. Brain 2012 135:784-793.

6. Cooper-Knock J, Hewitt C, Highley JR, Brockington A, Milano A, Man S, Martindale J, Hartley J, Walsh T, Gelsthorpe C, Baxter L, Forster G, Fox M, Bury J, Mok K, McDermott CJ, Traynor BJ, Kirby J, Wharton SB, Ince PG, Hardy J, Shaw PJ: Clinico-pathological features in amyotrophic lateral sclerosis with expansions in C9ORF72. Brain 2012, 135:751-764.

7. Rohrer JD, Warren JD: Phenotypic signatures of genetic frontotemporal dementia. Curr Opin Neurol 2011, 24:542-549.

8. Boeve BF, Boylan KB, Graff-Radford NR, DeJesus-Hernandez M, Knopman DS, Pedraza O, Vemuri P, Jones D, Lowe V, Murray ME, Dickson DW, Josephs KA Rush BK, Machulda MM, Fields JA, Ferman TJ, Baker M, Rutherford NJ, Adamson J, Wszolek ZK, Adeli A, Savica R, Boot B, Kuntz KM, Gavrilova R, Reeves A, Whitwell J, Kantarci K, Jack CR Jr., Parisi JE, Lucas JA, Petersen RC, Rademakers R: Characterization of frontotemporal dementia and/or amyotrophic lateral sclerosis associated with the GGGGCC repeat expansion in C9ORF72. Brain 2012, 135:765-783.

9. Simón-Sánchez J, Dopper EG, Cohn-Hokke PE, Hukema RK, Nicolaou N,
Seelaar H, de Graaf JR, de Koning I, van Schoor NM, Deeg DJ, Smits M, Raaphorst J, van den Berg LH, Schelhaas HJ, De Die-Smulders CE, MajoorKrakauer D, Rozemuller AJ, Willemsen R, Pijnenburg YA, Heutink P, van Swieten JC: The clinical and pathological phenotype of C9ORF72 hexanucleotide repeat expansions. Brain 2012, 135:723-735.

10. Mahoney CJ, Beck J, Rohrer JD, Lashley T, Mok K, Shakespeare T, Yeatman T, Warrington EK, Schott JM, Fox NC, Rossor MN, Hardy J, Collinge J, Revesz T, Mead S, Warren JD: Frontotemporal dementia with the C9ORF72 hexanucleotide repeat expansion: clinical, neuroanatomical and neuropathological features. Brain 2012, 135:736-750.

11. Whitwell IL, Weigand SD, Boeve BF, Senjem ML, Gunter JL, DeJesusHernandez M, Rutherford NJ, Baker M, Knopman DS, Wszolek ZK, Parisi JE, Dickson DW, Petersen RC, Rademakers R, Jack CR Jr., Josephs KA: Neuroimaging signatures of frontotemporal dementia genetics: C9ORF72, tau, progranulin and sporadics. Brain 2012, 135:794-806.

12. Boxer AL, Mackenzie IR, Boeve BF, Baker M, Seeley WW, Crook R, Feldman H, Hsiung GY, Rutherford N, Laluz V, Whitwell J, Foti D, McDade E, Molano J, Karydas A, Wojtas A, Goldman J, Mirsky J, Sengdy P, Dearmond S, Miller BL, Rademakers R: Clinical, neuroimaging and neuropathological features of a new chromosome 9p-linked FTD-ALS family. J Neurol Neurosurg Psychiatr 2011, 82:196-203.

13. Sha SJ, Takada LT, Rankin KP, Yokoyama JS, Rutherford NJ, Fong JC, Khan BK Karydas A, Baker MC, DeJesus-Hernandez M, Pribaldi M, Coppola G, Geschwind DH, Rademakers R, Lee SE, Seeley W, Miller BL, Boxer A: Frontotemporal dementia due to C9ORF72 mutations: Clinical and imaging features. Neurology 2012, 79:1002-1011.

14. Khan BK, Yokoyama JS, Takada LT, Sha SJ, Rutherford NJ, Fong JC, Karydas AM, Wu T, Ketelle RS, Baker MC, Hernandez MD, Coppola G, Geschwind DH, Rademakers R, Lee SE, Rosen HJ, Rabinovici GD, Seeley WW, Rankin KP, Boxer AL, Miller BL: Atypical, slowly progressive behavioural variant frontotemporal dementia associated with C9ORF72 hexanucleotide expansion. J Neurol Neurosurg Psychiatr 2012, 83:358-364.

15. Al-Sarraj S, King A, Troakes C, Smith B, Maekawa S, Bodi I, Rogelj B, Al-Chalabi A, Hortobagyi T, Shaw CE: p62 positive, TDP-43 negative, neuronal cytoplasmic and intranuclear inclusions in the cerebellum and hippocampus define the pathology of C9orf72-linked FTLD and MND/ ALS. Acta Neuropathol 2011, 122:691-702.

16. Murray ME, DeJesus-Hernandez M, Rutherford NJ, Baker M, Duara R, GraffRadford NR, Wszolek ZK, Ferman TJ, Josephs KA, Boylan KB, Rademakers R, Dickson DW: Clinical and neuropathologic heterogeneity of c9FTD/ALS associated with hexanucleotide repeat expansion in C9ORF72. Acto Neuropathol 2011, 122:673-690.

17. Hsiung GY, DeJesus-Hernandez M, Feldman HH, Sengdy P, Bouchard-Kerr P Dwosh E, Butler R, Leung B, Fok A, Rutherford NJ, Baker M, Rademakers R, Mackenzie IR: Clinical and pathological features of familial frontotemporal dementia caused by C9ORF72 mutation on chromosome 9p. Brain 2012, 135:709-722

18. Snowden JS, Rollinson S, Thompson JC, Harris JM, Stopford CL, Richardson AM, Jones M, Gerhard A, Davidson YS, Robinson A, Gibbons L, Hu Q, DuPlessis D, Neary D, Mann DM, Pickering-Brown SM: Distinct clinical and pathological characteristics of frontotemporal dementia associated with C9ORF72 mutations. Brain 2012, 135:693-708.

19. Floris $G$, Borghero $G$, Cannas A, Di Stefano F, Costantino E, Murru MR, Brunetti M, Restagno G, Traynor BJ, Marrosu MG, Chiò A, Marrosu F: Frontotemporal dementia with psychosis, parkinsonism, visuo-spatial dysfunction, upper motor neuron involvement associated to expansion of C9ORF72: a peculiar phenotype? J Neuro/ 2012, 259:1749-1751.

20. Whitwell JL, Jack CR, Boeve BF, Senjem ML, Baker M, Rademakers R, Ivnik RJ, Knopman DS, Wszolek ZK, Petersen RC, Josephs KA: Voxel-based morphometry patterns of atrophy in FTLD with mutations in MAPT or PGRN. Neurology 2009, 72:813-820.

21. Robertson NP: The C9ORF72 syndrome: implications for clinical practice. J Neurol 2012, 259:794-796.

22. Rohrer JD, Geser F, Zhou J, Gennatas ED, Sidhu M, Trojanowski JQ, Dearmond SJ, Miller BL, Seeley WW: TDP-43 subtypes are associated with distinct atrophy patterns in frontotemporal dementia. Neurology 2010, 75:2204-2211.

23. Whitwell JL, Jack CR Jr., Parisi JE, Senjem ML, Knopman DS, Boeve BF, Rademakers R, Baker M, Petersen RC, Dickson DW, Josephs KA: Does TDP-43 type confer a distinct pattern of atrophy in frontotemporal lobar degeneration? Neurology 2010, 75:2212-2220. 
24. Mackenzie IR, Neumann M, Baborie A, Sampathu DM, Du Plessis D, Jaros E, Perry RH, Trojanowski JQ, Mann DM, Lee VM: A harmonized classification system for FTLD-TDP pathology. Acta Neuropathol 2011, 122:111-113.

25. Rohrer JD, Ridgway GR, Modat M, Ourselin S, Mead S, Fox NC, Rossor MN, Warren JD: Distinct profiles of brain atrophy in frontotemporal lobar degeneration caused by progranulin and tau mutations. Neuroimage 2010, 53:1070-1076

26. Whitwell JL, Weigand SD, Gunter UL, Boeve BF, Rademakers R, Baker M, Knopman DS, Wszolek ZK, Petersen RC, Jack CR Jr., Josephs KA: Trajectories of brain and hippocampal atrophy in FTD with mutations in MAPT or GRN. Neurology 2011, 77:393-398.

27. Seeley WW: Selective functional, regional, and neuronal vulnerability in frontotemporal dementia. Curr Opin Neurol 2008, 21:701-707.

28. Zhou J, Gennatas ED, Kramer JH, Miller BL, Seeley WW: Predicting regional neurodegeneration from the healthy brain functional connectome. Neuron 2012, 73:1216-1227.
29. Schmahmann JD, Smith EE, Eichler FS, Filley CM: Cerebral white matter: neuroanatomy, clinical neurology, and neurobehavioral correlates. Ann NY Acad Sci 2008, 1142:266-309.

30. Schmahmann JD, Pandya DN: Disconnection syndromes of basal ganglia, thalamus, and cerebrocerebellar systems. Cortex 2008, 44:1037-1066.

31. Takada LT PM, DeJesus-Hernandez M, Fong JC, Yokoyama JS, Karydas A, Thibodeau MP, Rutherford NJ, Baker MC, Lomen-Hoerth C, Rademakers R, Miller BL: Frontotemporal Dementia in a Brazilian Caucasian kindred with the C9orf72 mutation. Arch Neurol 2012, 69:1149-1153.

doi:10.1186/alzrt148

Cite this article as: Yokoyama JS, Rosen HJ: Neuroimaging features of C9ORF72 expansion. Alzheimer's Research \& Therapy 2012, 4:45. 